\title{
Thermosensitive Brinzolamide in situ Gel Nanoemulsions, in vitro and ex vivo Evaluation
}

\author{
Mohammad Mehdi Mahboobian ${ }^{1}$, Golsa Mohammadi ${ }^{2}$, Mojdeh Mohammadi 2* (D) \\ 1 Department of Pharmaceutics, School of Pharmacy, Hamadan University of Medical Sciences, Hamadan, Iran \\ 2 Department of Toxicology and Pharmacology, School of Pharmacy, Hamadan University of Medical Sciences, Hamadan, \\ Iran \\ * Correspondence: m.mohammadi@umsha.ac.ir;
}

Scopus Author ID 55625871400

Received: 26.05.2020; Revised: 27.06.2020; Accepted: 29.06.2020; Published: 3.07.2020

\begin{abstract}
Brinzolamide (BZ) is a carbonic anhydrase inhibitor with selectivity and affinity for the carbonic anhydrase type II isoenzyme that administrated topically as an ophthalmic suspension for reducing intraocular pressure. In this study, BZ in situ gel nanoemulsions (NEs) were developed and evaluated for transcorneal permeation via the bovine corneal membrane. The spontaneous emulsification method was employed to prepare BZ in situ gel NEs. Various physicochemical characteristics, including particle size, polydispersity index, $\mathrm{pH}$, refractive index, and viscosity, were evaluated. Accelerated physical stability and in vitro drug release, as well as transcorneal permeation studies was performed by applying the Franz-type diffusion cells. Thermosensitive BZ in situ gel NEs with desired physicochemical features and sustained release profiles were designed in the current study. Optimized Formulations exhibited physical stability under different conditions. The transcorneal permeation of formulations was higher than that of suspension, especially for F3b formulation. According to the present in vitro and ex vivo evaluations, it is concluded that in situ gel NEs could be a topical administration of BZ as a suitable ocular drug delivery system.
\end{abstract}

Keywords: Brinzolamide; Nanoemulsion; Transcorneal permeation; in situ gel.

(C) 2020 by the authors. This article is an open-access article distributed under the terms and conditions of the Creative Commons Attribution (CC BY) license (https://creativecommons.org/licenses/by/4.0/).

\section{Introduction}

Ocular drug delivery is a challenging issue in pharmacotherapy. The unique physiological structure of the eye limits the delivery of the drug to the target site. The available ophthalmic drugs (more than 90\% ) are used as eye drops to deliver drugs to the anterior part of the eye. Despite the ease of use and compliance of patients, less than $5 \%$ of the instilled eye drops enter the eye [2]. The washout of the applied droplets through different mechanisms, including blinking and tearing, are the main reasons for lowering the ocular bioavailability of drugs. Another limiting factor in ocular drug delivery is corneal tissue characteristics. In general, corneal tissue consists of three main layers as epithelium, stroma, and endothelium. The corneal epithelium has a lipophilic structure; hence, the permeability of lipophilic drugs is higher. Stroma has a hydrophilic structure that forms $90 \%$ of corneal tissue. The endothelium is a single layer responsible for moisturizing the cornea. Therefore, this dual structure is an effective barrier that reduces the permeability of both hydrophilic and hydrophobic drugs. In the pharmaceutical industry, bioavailability is improved by adding viscous substances such as hydroxyethyl cellulose to eye drops, gels, and ointments [3-5]. 
Glaucoma is characterized by increased intraocular pressure (IOP), atrophy of the optic nerve, and visual disturbance. It is the second most common cause of blindness worldwide, of which $12 \%$ are preventable. It is predictable that by 2020, nearly four million Americans and 80 million people worldwide will have the disease [6,7]. Glaucoma is categorized based on different systems, but it is generally known in two types: open-angle and closed-angle. In openangle glaucoma, there is a problem in the drainage canal of the vitreous humor in the trabecular meshwork, Schlemm's canal. In closed-angle glaucoma, due to the obstruction of the trabecular meshwork by the peripheral part of the iris, resistance is created to the outflow of clear fluid $[8,9]$. Drugs used to treat glaucoma reduce IOP through two mechanisms: reducing the production of aqueous humor in the ciliary body and increasing the aqueous humor drainage [8-10]. Brinzolamide (BZ) is a specific, reversible, non-competitive inhibitor of carbonic anhydrase II enzyme. The inhibition of this enzyme prevents the secretion of vitreous humor and subsequently reduces IOP. BZ is an effective drug in lowering the elevated IOP associated with ocular hypertension or open-angle glaucoma. BZ is a poorly water-soluble powder and has been developed and supplied as a sterile, aqueous ophthalmic suspension formulated at physiological $\mathrm{pH}$ [11-15]. In a meta-analysis of clinical trials on various anti-glaucoma drugs, the use of BZ as a single-drug therapy to treat glaucoma can reduce IOP by $17 \%$ [16]. Numerous studies showed the efficacy of BZ as the first-line treatment for glaucoma in a single or combination regimen. These studies showed increased efficacy of this drug in combination therapy with other IOP reducing agents, including Timolol and prostaglandin analogs $[12,17$, 18]. The effective dose frequency of this drug is 2-3 times a day, which is one of the factors lowering the compliance of patients. On the other hand, the suspension of BZ requires dissolution in the anterior corneal space to increase efficacy, which may lead to reduced bioavailability of the drug due to the washout mechanisms that remove the drug from the eye surface [19].

The application of nanosystems, such as nanoemulsions [1], is one of the most suitable approaches to increase the efficacy of topical eye drugs. NEs, due to possessing various properties such as low cost of manufacturing, ease of sterilization, high stability, low viscosity, high solubility, drug sustainability and adherence of oil droplets to the eye epithelium surface (reservoir formation), and preventing the drug washout and removal from the eye surface, are considered as new carriers for ophthalmic drug delivery [20-22]. NEs are lipid-based formulations with droplet size in the nanometric range that are highly applicable in pharmaceutical purposes [20, 23].

The use of in situ gel systems has also received a lot of attention due to their advantages including less blurred vision compared to the ophthalmic ointments, improved ocular bioavailability due to increased drug longevity in the cornea and greater absorption rate, lack of hepatic first-pass effect, ease of use in comparison with inserts, lower frequency of drug application compared with other forms of the drug, and developed patient agreement and comfort. These systems are made of polymers that can convert the liquid form of the product to the gel form at the site of administration. The ocular in situ gel drug is a liquid product that can convert into a more viscous form when places in the Cul De Sac. This occurs under the influence of environmental conditions such as temperature, $\mathrm{pH}$ changes, and ion presence. Polymers using for in situ gel systems should possess biocompatible, non-irritating, and mucosal-binding features, and also represent plastic-like behaviors [24-28]. In the current study, the in situ gel-based BZ NE was designed as an ocular drug delivery system, and transcorneal permeation was evaluated in an ex vivo model. 


\section{Materials and Methods}

\subsection{Materials.}

BZ and Transcutol ${ }^{\circledR} \mathrm{P}$ were gifted from Bachem, Switzerland, and Gattefosse, France, respectively. Triacetin (glycerol Triacetate) was obtained from Samchun chemical co., Ltd, South Korea. Dialysis tubing cellulose membrane, Poloxamer 407, and Poloxamer 188 were provided from Sigma chemical company, USA. All other chemicals and solvents were of analytical grade.

\subsection{Phase diagrams construction.}

Phase diagrams were used to determine the nanoemulsion area and the concentration of each nanoemulsion component. Phase diagrams were composed of different weight ratios of surfactant-cosurfactant (Smix) (Rsm: 1:2, 2:1, 1: 3, 3:1 and 1:1). The Triacetin as an oil, the Twin 80 as a surfactant, and the Transcutol ${ }^{\circledR} \mathrm{P}$ as a cosurfactant were poured into screw-cap glass vials with different Smix /oil ratios from 90:10 to 10:90 to make each phase diagram. Then, distilled water was added drop by drop into the mixture under stirring at room temperature. The samples were visually checked for a transparent/translucent area, and finally, the phase diagrams were achieved by Sigma-Plot ver.12 software (Figure 1).

\subsection{Preparation of BZ in situ gel NEs.}

Based on the phase diagrams results, the appropriate weight ratio containing $10 \%$ of the mixture of surfactant and cosurfactant and $2.5 \%$ of the oil and $0.5 \%$ of the BZ was selected as the NE formula which was entered into the aqueous phase including Poloxamer 407 and 188 with different weight ratios to prepare in situ gel NEs. Spontaneous emulsification method was carried out to develop BZ in situ gel NEs, at the first step, intended amount of Poloxamer(s) and water stirred in the ice bath for a minimum $2 \mathrm{~h}$ and then added to the homogenous mixture of NE formula. Finally, this homogenous mixture was stirred in the ice bath for $1 \mathrm{~h}$ further to achieve the in situ gel NEs.

\subsection{Determination of gelation temperature.}

To determine the temperature of gelation, $0.5 \mathrm{ml}$ of each formulation was added into the microtube and placed in a hot water bath (Memmert ONE 10, Germany) at $15^{\circ} \mathrm{C}$, and then the temperature was increased $1{ }^{\circ} \mathrm{C} / \mathrm{min}$. Those formulations which were gelled at the nearest temperature to the eye $\left(31-34^{\circ} \mathrm{C}\right)$ were selected.

\subsection{Physicochemical characterization.}

The particle size and polydispersity index (PDI) of BZ NEs were measured by a Malvern Zetasizer NanoZS (Malvern, United Kingdom). The refractive index (RI) of samples was determined at $25{ }^{\circ} \mathrm{C}$ by the Refractometer (Atago refractometer, Model 3T, Japan). $\mathrm{pH}$ of samples was measured by a $\mathrm{pH}$ meter (Sartorius, Germany) at $25^{\circ} \mathrm{C}$. Rheological properties were measured and determined using spindle CP-34 by Brook field DVII Viscometer (Brook field engineering laboratories Inc. USA) $\left(25-200 \mathrm{rpm}, 0.25 \pm 0.5^{\circ} \mathrm{C}\right)$. The viscosity was determined using rheogram, which was formed by plotting the shear stress (dynes $/ \mathrm{cm}^{2}$ ) against the shear rate $\left(\mathrm{s}^{-1}\right)$. All measurements were achieved in triplicate and presented as mean $\pm \mathrm{SD}$. 


\subsection{In vitro drug release studies.}

The release behavior of BZ NEs was studied by the dialysis bag method. Initially, a cellulose dialysis bag (MW cut-off $12,400 \mathrm{Da}$ ) was soaked in distilled water $4{ }^{\circ} \mathrm{C}$ for $24 \mathrm{~h}$, and then, 750 microliters of each formulation were poured into dialysis bag. The dialysis bag was connected to the USP paddle II with $50 \mathrm{rpm}$ rotation in $250 \mathrm{~mL}$ release medium containing phosphate buffer $(\mathrm{pH}=7.4)$. Similar to the surface temperature of the eye, the temperature was set to $34.0 \pm 0.2^{\circ} \mathrm{C}$ [29]. Release studies were carried out for $6 \mathrm{~h}$ under sink conditions, and at defined intervals $(15,30,45,60,120,180,240,300$, and $360 \mathrm{~min}) 1 \mathrm{~mL}$ of medium was taken out and replaced with fresh medium. The releasing amount of BZ from NEs was measured at each interval with UV spectrophotometry at $254 \mathrm{~nm}$, and the release efficiency (RE) rate was calculated using the following formula [30]:

$$
\frac{\int_{0}^{t} y \times d t}{y 100 \times t} \times 100=R E \quad \text { Eq. } 1
$$

, where $y$ refers to drug release percentage at time $t$.

\subsection{Accelerated physical stability tests.}

Different procedures, including heating-cooling and freeze-thaw cycles as well as centrifugation, were performed to monitor the physical stability of BZ NEs. All samples were then monitored for phase separation, clarity, and physical instability. Six cycles were performed between 4 and $40{ }^{\circ} \mathrm{C}$ for at least $48 \mathrm{~h}$ [31]. Freeze-thaw cycles were performed at three stages between -21 and $+25{ }^{\circ} \mathrm{C}$ in which samples were stored for at least $48 \mathrm{~h}[1,32,33]$. Those formulations which passed the previous tests were centrifuged at 13,000 rpm for $30 \mathrm{~min}$ $[29,34]$.

\subsection{Ex vivo transcorneal permeation test.}

Franz-type diffusion cells with two compartments of the donor $(17 \mathrm{~mm}$ orifice diameter and $2.27 \mathrm{~cm}^{2}$ diffusion area) and receptor (12 $\mathrm{ml}$ volume) were used to perform corneal permeation tests by excised bovine eyes. Corneas were detached from other tissues. Detached corneas were placed between the two mentioned compartments. Simulation of ocular condition was achieved by filling the receptor compartment with buffer phosphate $(\mathrm{pH}=7.4)$, which was continuously stirring, and maintaining the temperature at $34 \pm 1^{\circ} \mathrm{C}$ by a circulator bath. Sampling was done at 30, 60, 90, 120, 180, 240, 300, and 360 min, under sink condition. After each time of sampling $(0.5 \mathrm{~mL}$ was withdrawn), an equivalent volume of fresh buffer phosphate was replaced immediately. Finally, samples were measured by UV spectroscopy method at $254 \mathrm{~nm}$.

\subsection{Statistical analysis.}

One-way ANOVA followed by Tukey's post-hoc test was used for statistical analyses in Graph Pad Prism 7. The experiments were performed in triplicate, and the results expressed as mean \pm SD. $P<0.05$ was considered as the level of significance. 


\section{Results and Discussion}

\subsection{Construction of pseudo-tertiary phase diagrams.}

The present experimental study aimed to design an in situ gel formulation to deliver BZ to the eye. In the present study, to design an oil-in-water NE system, Triacetin as oil, Tween 80 as a surfactant, and Transcutol ${ }^{\circledR} \mathrm{P}$ as cosurfactant were used. To determine the NE region, the tertiary phase diagram was plotted, and five different weight ratios $(1: 2,2: 1,3: 1,1: 3$, and 1: 1) of surfactant and cosurfactant (Rsm) were served to study the phase behavior. The main purpose of evaluating the phase behavior of the mixture was to determine the NE region of the oil-in-water, in which the mixture was clear (or had a blue light reflection) and thermodynamically stable (or rather stable). In the tertiary phase diagrams, the upper apex was considered as the region of surfactant/cosurfactant mixture with a certain ratio; the lower-left apex was considered as the aqueous phase and the lower right apex as the oil phase. The tertiary phase diagram plotted in five different surfactant/cosurfactant ratios showed that as the surfactant/co-surfactant ratio decrease in each diagram, the NE area increases. In the plotted phase diagrams (Figure 1), the NE domain was more extensive at a surfactant/cosurfactant ratio of 1:3 than other ratios. This enhancement of NE region can be attributed to the higher oil solubilizing capacity due to the increased concentration of Transcutol ${ }^{\circledR} \mathrm{P}$. Based on the extensive NE region, the Rsm of 1:3 was selected as the optimal ratio of Smix for the preparation of NE.

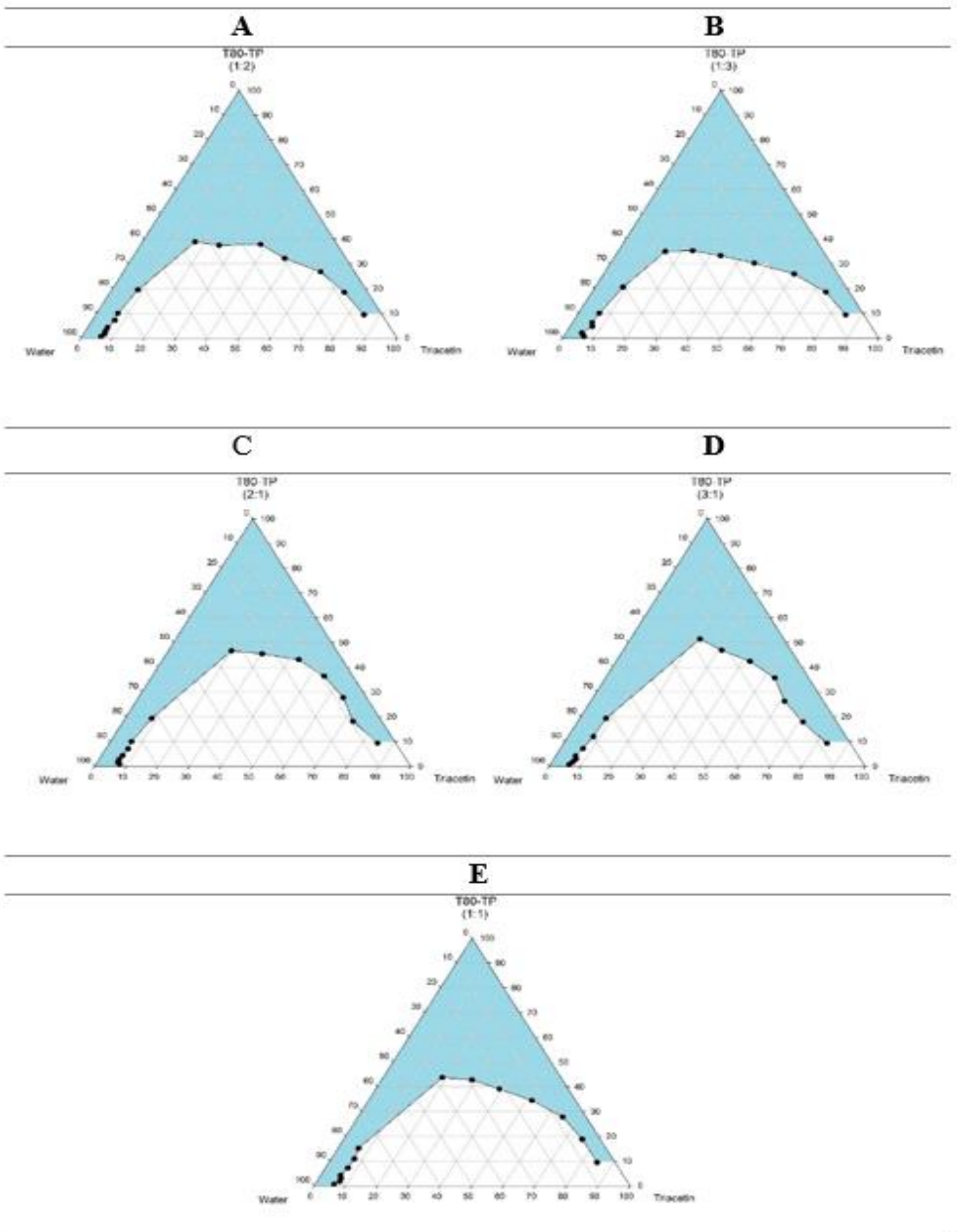

Figure 1. Phase diagrams of systems composed of Triacetin, Transcutol ${ }^{\circledR} \mathrm{P}$ at various Smix weight ratios: A) $1: 2$, B) $1: 3$, C) $2: 1$, D) $3: 1$, E) 1:1 (Colored area of each plot represents NE region). 


\subsection{Development of BZ in situ gel NEs.}

Based on the plotted tertiary phase diagrams, the formulation with 1:3 Smix ratio, including $2.5 \%$ of Tween 80 and $7.5 \%$ of Transcutol ${ }^{\circledR} \mathrm{P}$ as a surfactant and co-surfactant respectively, $2.5 \%$ Triacetin as an oil, and $0.5 \%$ of $\mathrm{BZ}$ as the active ingredient was selected as a NE base. As mentioned in Table 1, various in situ gel NEs were developed by using different ratios of the Poloxamer 407 and 188.

\subsection{Gelation temperature of in situ gel NEs.}

Poloxamers are polymers with two hydrophilic (polyethylene oxide; PEO) and hydrophobic (polypropylene oxide; PPO) parts [35]. The gelation temperature of Poloxamers depends on their PEO: PPO ratios. The PEO section is responsible for the higher gelation temperature and the PPO part, in turn, reduce the gelation temperature of the polymer. A combination of these two properties makes them the thermo-sensitive gel polymers that can convert from the liquid into a gel form by raising the temperature. Therefore, PEO:PPO ratio is a key factor in the gelation temperature of Poloxamers [35]. Since the current study aimed at designing a thermosensitive in situ gel-based NE as an ocular drug delivery system, suitable concentrations of Poloxamers to convert liquid NEs into the gel form at the temperature range of $30-35^{\circ} \mathrm{C}$, near the temperature of the eye surface, were required [11]. According to studies, first, Poloxamer 407 at three concentrations of $12 \%, 14.5 \%$, and $17 \%$ was used. The concentration of $12 \%$ with a gelation temperature of above $40{ }^{\circ} \mathrm{C}$ was excluded from the study. After that, two concentrations of $14.5 \%$ and $17 \%$ were used. At $14.5 \%$ concentration, $14.2 \%$ Poloxamer 407 and $0.3 \%$ Poloxamer 188 were used in which the gelation temperature was $33.36{ }^{\circ} \mathrm{C}$, and the rest of the ratios were below $30{ }^{\circ} \mathrm{C}$ and above $40{ }^{\circ} \mathrm{C}$; at $17 \%$ concentration, 15.5\% Poloxamer 407 and $1.5 \%$ Poloxamer 188 were used in which the gelation temperature was $32.66{ }^{\circ} \mathrm{C}$ that was within the desired range for converting into gel form in the eye. The other two ratios were out of the acceptable range (Table 1). Therefore these two formulations were selected for further investigations.

Table 1. The gelation temperature of various in situ gel NEs (mean $\pm S D, n=3$ ).

\begin{tabular}{|c|c|c|c|c|}
\hline Formulation & $\begin{array}{c}\text { Poloxamer } 407 \\
(\mathrm{~W} / \mathrm{w} \%)\end{array}$ & $\begin{array}{c}\text { Poloxamer } 188 \\
(\mathrm{~W} / \mathrm{w} \%)\end{array}$ & $\begin{array}{c}\text { Gelation temperature } \\
\left({ }^{\circ} \mathrm{C}\right)\end{array}$ & \\
\hline F1 & 12 & 0 & $>40$ & $\theta^{\circ}$ \\
\hline $\mathrm{F} 2$ & 14.5 & 0 & $28.63 \pm 0.85$ & $b^{0} \frac{3}{3}$ \\
\hline $\mathrm{F} 2 \mathrm{a}$ & 14.35 & 0.15 & $29.63 \pm 0.61$ & \\
\hline F2b* & 14.2 & 0.3 & $33.37 \pm 0.93$ & $\begin{array}{ll}3 \\
3 \pi\end{array}$ \\
\hline F2c & 13.9 & 0.6 & $>40$ & 0 \\
\hline $\mathrm{F} 3$ & 17 & 0 & $20.70 \pm 0.46$ & $\Xi$ \\
\hline $\mathrm{F} 3 \mathrm{a}$ & 16 & 1 & $29.27 \pm 0.50$ & 00 \\
\hline F3b* & 15.5 & 1.5 & $32.67 \pm 0.86$ & 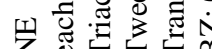 \\
\hline F3c & 15 & 2 & $36.80 \pm 0.89$ & \\
\hline
\end{tabular}

*Selected for further evaluations

\subsection{Physicochemical characterization.}

Particle size is one of the most important factors in ophthalmic drug delivery, Nanometric particles show more adherence of drug on the surface of the eye and elevate drug penetration to the eye tissues by enhancement of surface area [36]. The particle size of the F2b and F3b were $27.3 \pm 3.97$ and $26.4 \pm 2.99$ in the nanometer range, respectively. The reduction in the radius of curvature of the droplets is caused by the presence of cosurfactant and its penetration into the interfacial film of oil droplets of the NE system [37]. The prepared 
nanoemulsion systems had a PDI in the range of $0.29 \pm 0.07$ and $0.30 \pm 0.05$. PDI value $<0.5$ indicates narrow size distribution along with the spherical shape of the particles [38].

The designed-in situ NEs also had RI (1.35 and 1.36) values near the RI of tear fluid (1.34). The acceptable RI range of the ophthalmic products is less than 1.476, and those with higher RIs might cause ocular problems and blurred vision [39, 40]. The ideal $\mathrm{pH}$ for ophthalmic products is approximately 7.2 [41]. If there is a far distance between the $\mathrm{pH}$ value of tear and ophthalmic products, consumption may result in pain and irritation [16]. As shown in Table 2, both formulations had $\mathrm{pH}$ less than 6; however, tear, due to its buffering capacity, can adjust the $\mathrm{pH}$ of ophthalmic products according to the physiological conditions of the eye. Therefore, ph of prepared samples is in the acceptable $\mathrm{pH}$ range of pharmaceutical eye products $(3.5$ to 8.5$)[39,42]$.

Retention of the instilled liquid formulations on the surface of eyes is one of the main factors affecting ocular drug delivery. The longevity of the drug on the eye surface greatly depends on its viscosity. High viscosity increases the longevity of the drug on the eye surface and, consequently, its bioavailability, but on the other hand, it may cause problems such as difficulty in the application to the eye surface, pain, excessive blinking, etc. [16]. Therefore, the viscosity of ophthalmic drugs should be within a certain range that is compatible with eye conditions. It is recommended that the viscosity of topical ophthalmic products should not exceed $25 \mathrm{cP}$ [43]. As a result of the solid nature of Poloxamer at room temperature, the NE systems containing this compound have an almost high viscosity [44]. Therefore, the viscosity of prepared NEs is higher than recommended viscosity value, but in several studies, the installation of high viscose formulations exhibited no irritancy in the rabbit eyes $[45,46]$. It is noteworthy that an increased concentration of Poloxamers in F3b formulation compared to F2b, led to more increased viscosity value.

Table 2. Physicochemical characterization of BZ in situ gel NEs (mean $\pm \mathrm{SD}, \mathrm{n}=3$ ).

\begin{tabular}{c|c|c|c|c|c|c} 
F2b & Mean & SD & F3b & Mean & SD \\
\hline Size & 27.369 & 3.971 & & Size & 26.417 & 2.998 \\
\hline PDI & 0.293 & 0.070 & & PDI & 0.306 & 0.052 \\
\hline pH & 5.917 & 0.144 & pH & 5.503 & 0.055 \\
\hline RI & 1.358 & 0.004 & & RI & 1.366 & 0.003 \\
\hline Viscosity & 41.283 & 4.421 & & Viscosity & 81.657 & 2.031
\end{tabular}

\subsection{In vitro drug release.}

Studying the process of drug release from colloidal drug delivery systems, including NEs, facilitates prediction of their behavior in vivo, the point that is one of the major features of these systems. Accordingly, the process of drug release from NE formulations was compared with that of the suspension using the dialysis bag method. RE percent of the drug was calculated and presented in Table 3 and Figure 2.

Table 3. Release efficiency of BZ in situ gel NEs after $6 \mathrm{~h}$ (mean $\pm \mathrm{SD} ; \mathrm{n}=3$ ).

\begin{tabular}{l|c|c} 
Formulation & Release Efficiency $(\%)$ & Statistical evaluation \\
\hline SUSP & $72.92 \pm 2.43$ & - \\
\hline F2b & $60.11 \pm 5.36$ & $p<0.05$ \\
\hline F3b & $56.79 \pm 2.77$ & $p<0.01$
\end{tabular}




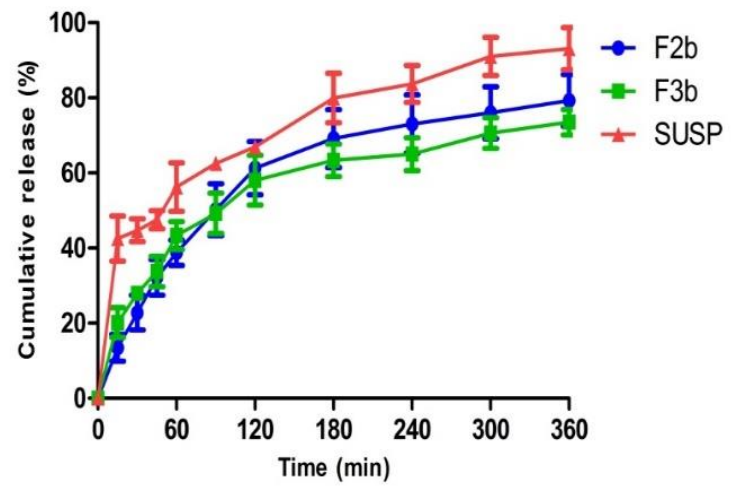

Figure 2. Release profile of samples during $6 \mathrm{~h}($ mean $\pm S D ; n=3)$.

The release of the drug from the oil-in-water NE is the result of entering the drug from oil phase the interfacial region into the aqueous phase. Various factors such as the particle size, the components of the systems, and viscosity can affect drug release from such systems. For example, smaller particle size increases the release of drugs by creating more contact surfaces. Due to the composition of the NE system and the high viscosity of this system, the drug trapped in the oil droplets slowly enters the liquid phase from the oil phase, which prolongs the duration of drug release [39]. According to the drug release diagram (Figure 2), the loaded drug was released from the designed NE systems, more than $50 \%$ after $2 \mathrm{~h}$. A more sustained drug release rate was observed with the prepared formulations compared with the control suspension. Although no significant difference was observed in the RE\% between both formulations, However, it seems higher viscosity of F3b versus F2b led to a slower release of BZ from F3b formulation. In a study by Morsi et al., oil-in-water NEs for ophthalmic drug delivery with higher viscosity had a slower release rate than other samples [46]; the same results were also obtained by Idrees et al. [47].

\subsection{Accelerated physical stability tests.}

To investigate accelerated physical stability of two selected formulations, heatingcooling, and freeze-thaw cycles, as well as centrifugation, were performed, and the results indicated the optimal physical stability of all the samples so that no instability such as phase separation, cracking, and creaming was observed. Only the storage of the samples in the freezer made them turbid, which cleared again after being placed at room temperature. Also, all samples were stable at the refrigerator. It seems that the temporary instability in the freezer was due to the adhesion of the internal phase droplets and the pressure of the ice crystals on the interfacial film [48].

\subsection{Ex vivo transcorneal permeation.}

The permeation profile of the two NE formulations and the suspension through the bovine corneal membrane has been shown in Table 4. Based on these results, F3b enhanced corneal permeation of BZ in comparison with suspension significantly, which can be explained by the presence of surfactant and cosurfactant $\left(\mathrm{S}_{\mathrm{mix}}\right)$, leading to disruption of the tight junction of corneal membrane cells [49]. Moreover, corneal epithelium cells can uptake nano-sized droplets by endocytosis [50]. It seems that the higher content of Poloxamer 188 and 407 with surfactant properties in $\mathrm{F} 3 \mathrm{~b}$ formulation compared to the $\mathrm{F} 2 \mathrm{~b}$, resulted in additional permeation of BZ. 
Table 4. Corneal permeation profile of BZ in situ gel NEs through the bovine corneal membrane $($ mean $\pm \mathrm{SD} ; \mathrm{n}=3)$.

\begin{tabular}{|c|c|c|c|}
\hline Formulation Code & $P_{\text {app }}\left(\times 10^{-6} \mathrm{~cm} / \mathrm{s}\right)$ & $\mathbf{R} \mathbf{P}_{\text {app }}$ & Statistical analysis \\
\hline SUSP & $3.76 \pm 0.78$ & - & - \\
\hline F2b & $4.20 \pm 0.11$ & 1.12 & non-significant \\
\hline F3b & $5.95 \pm 0.82$ & 1.58 & $p<0.05$ \\
\hline
\end{tabular}

\section{Conclusions}

BZ was offered in a suspension form to the pharmaceutical market as a highly effective drug in the treatment of glaucoma, but its prescription was limited due to its dose frequency and side effects such as blurred vision and feeling of a foreign body in the eye. An approach to overcome these limitations was the point of using in situ gel NEs as drug carriers. In the current study, the thermosensitive BZ in situ gel NEs were designed for ophthalmic delivery. Due to the optimum size of formulations and other physicochemical properties, prolong release patterns, and also improved transcorneal penetration, the designed formulations, specially F3b, had superior traits compared to the suspension form. The results of the study showed that the thermo-sensitive in situ gel-based NEs were prepared by a low-energy method that can be used as a suitable ocular drug delivery system of BZ.

\section{Funding}

The vice-chancellor of research comity endorses this research (Grant No. 970128377).

\section{Acknowledgments}

We would like to announce that the conducted research presented in this paper is a part of the Miss Golsa Mohammadi's doctorate result, which is in pharmacy funding of Hamadan University of Medical Sciences.

\section{Conflicts of Interest}

The authors declare no conflict of interest.

\section{References}

1. Soufdoost, R.S.; Yazdanian, M.; Tahmasebi, E.; Yazdanian, A.; Tebyanian, H.; Karami, A.; Nourani, M.R.; Panahi, Y. In vitro and in vivo evaluation of novel Tadalafil/ $\beta$-TCP/Collagen scaffold for bone regeneration: A rabbit critical-size calvarial defect study. Biocybern Biomed Eng 2019, 39, 789-796, https://doi.org/10.1016/j.bbe.2019.07.003.

2. Gaudana, R.; Ananthula, H.K.; Parenky, A.; Mitra, A.K. Ocular drug delivery. AAPS J 2010, 12, 348-360, https://doi.org/10.1208/s12248-010-9183-3.

3. Ali, Y.; Lehmussaari, K. Industrial perspective in ocular drug delivery. Adv Drug Deliv Rev 2006, 58, 125868, https://doi.org/10.1016/j.addr.2006.07.022.

4. Shakeri, F.; Tebyanian, H.; Karami, A.; Babavalian, H.; Tahmasbi, M.H. Effect of Topical Phenytoin on Wound Healing. Trauma. Mon 2017, 22.

5. Karami, A.; Tebyanian, H.; Barkhordari, A.; Motavallian, E.; Soufdoost, R.S.; Nourani, M.R. Healing effects of ointment drug on full-thickness wound. C. R. Acad. Bulg. Sci 2019, 72, 123-129.

6. Gooch, N.; Molokhia, S.A.; Condie, R.; Burr, R.M.; Archer, B.; Ambati, B.K.; Wirostko, B. Ocular drug delivery for glaucoma management. Pharmaceutics 2012, 4, 197-211, https://doi.org/10.3390/pharmaceutics4010197.

7. Reeder, C.E.; Franklin, M.; Bramley, T.J. Managed care and the impact of glaucoma. Am J Manag Care 2008, 14, S5-S10,

8. Alward, W.L.M. Medical management of glaucoma. N. Engl. J. Med 1998, 339, 1298-1307, https://doi.org/10.1056/nejm199810293391808. 
9. Saxena, R.; Prakash, J.; Mathur, P.; Gupta, S.K. Pharmacotherapy of glaucoma. Indian J. Pharmacol 2002, $34,71-85$,

10. Babavalian, H.; Latifi, A.M.; Shokrgozar, M.A.; Bonakdar, S.; Tebyanian, H.; Shakeri, F. Cloning and expression of recombinant human platelet-derived growth factor-BB in Pichia Pink. Cell Mol Biol (Noisyle-grand) 2016, 62, 45-51.

11. Edsman, K.; Carlfors, J.; Petersson, R. Rheological evaluation of Poloxamer as an in situ gel for ophthalmic use. Eur J Pharm Sci 1998, 6, 105-12, https://doi.org/10.1016/s0928-0987(97)00075-4.

12. Iester, M. Brinzolamide ophthalmic suspension: a review of its pharmacology and use in the treatment of open angle glaucoma and ocular hypertension. Clin Ophthalmol 2008, 2, 517-23, https://doi.org/10.2147/opth.s3182.

13. Moosavi, R.; Ansari, E. Brinzolamide/Brimonidine Fixed Combination: Simplifying Glaucoma Treatment Regimens. Ophthalmol Ther 2018, 7, 397-403, https://doi.org/10.1007/s40123-018-0150-X.

14. Wang, F.; Bao, X.; Fang, A.; Li, H.; Zhou, Y.; Liu, Y.; Jiang, C.; Wu, J.; Song, X. Nanoliposomeencapsulated brinzolamide-hydropropyl- $\beta$-cyclodextrin inclusion complex: a potential therapeutic ocular drug-delivery system. Front Pharmacol 2018, 9, https://doi.org/10.3389/fphar.2018.00091.

15. Young, J.W.; Clements, J.L.; Morrison, J.C.; Takusagawa, H.L. Brinzolamide-induced Follicular Conjunctivitis. J Glaucoma 2018, 27, e183-e184, https://doi.org/10.1097/IJG.0000000000001063.

16. van der Valk, R.; Webers, C.A.; Schouten, J.S.; Zeegers, M.P.; Hendrikse, F.; Prins, M.H. Intraocular pressure-lowering effects of all commonly used glaucoma drugs: a meta-analysis of randomized clinical trials. Ophthalmology 2005, 112, 1177-85, https://doi.org/10.1016/j.ophtha.2005.01.042.

17. Dong, Y.R.; Huang, S.W.; Cui, J.Z.; Yoshitomi, T. Effects of brinzolamide on rabbit ocular blood flow in vivo and ex vivo. Int J Ophthalmol 2018, 11, 719-725, https://doi.org/10.18240/ijo.2018.05.03.

18. Lerner, S.F.; Oddone, F.; Lu, D.W.; Sanseau, A.; Guarro, M.; Ridolfi, A.; Hubatsch, D. Maximum Medical Therapy: Brinzolamide/Brimonidine And Travoprost/Timolol Fixed-Dose Combinations In Glaucoma And Ocular Hypertension. Clin Ophthalmol 2019, 13, 2411-2419, https://doi.org/10.2147/OPTH.S228777.

19. Rajpoot, P.; Pathak, K.; Bali, V. Therapeutic applications of nanoemulsion based drug delivery systems: a review of patents in last two decades. Recent Pat Drug Deliv Formul 2011, 5, 163-72, https://doi.org/10.2174/187221111795471427.

20. Solans, C.; Izquierdo, P.; Nolla, J.; Azemar, N.; Garcia-Celma, M.J. Nano-emulsions. Curr. Opin. Colloid Interface Sci 2005, 10, 102-110, https://doi.org/10.1016/j.cocis.2005.06.004.

21. Liu, Q.; Huang, H.; Chen, H.; Lin, J.; Wang, Q. Food-Grade Nanoemulsions: Preparation, Stability and Application in Encapsulation of Bioactive Compounds. Molecules 2019, 24, https://doi.org/10.3390/molecules24234242.

22. Soufdoost, R.S.; Mosaddad, S.A.; Salari, Y.; Yazdanian, M.; Tebyanian, H.; Tahmasebi, E.; Yazdanian, A.; Karami, A.; Barkhordari, A. Surgical Suture Assembled with Tadalafil/Polycaprolactone Drug-Delivery for Vascular Stimulation Around Wound: Validated in a Preclinical Model. Biointerface Res Appl Chem 2020, 10, 6317-6327, https://doi.org/10.33263/BRIAC105.63176327.

23. Gutiérrez, J.M.; González, C.; Maestro, A.; Solè, I.; Pey, C.M.; Nolla, J. Nano-emulsions: New applications and optimization of their preparation. Curr. Opin. Colloid Interface Sci 2008, 13, 245-251, https://doi.org/10.1016/j.cocis.2008.01.005.

24. Kute, P.R.; Gondkar, S.B.; Saudagar, R.B. Ophthalmic in-situ gel: an overview. World J. Pharm. Pharm. Sci 2015, 4, 549-568,

25. Khomarlou, N.; Aberoomand-Azar, P.; Lashgari, A.P.; Tebyanian, H.; Hakakian, A.; Ranjbar, R.; Ayatollahi, S.A. Essential oil composition and in vitro antibacterial activity of Chenopodium album subsp. striatum. Acta Biologica Hungarica 2018, 69, 144-155, https://doi.org/10.1556/018.69.2018.2.4.

26. Seifi Kafshgari, H.; Yazdanian, M.; Ranjbar, R.; Tahmasebi, E.; Mirsaeed, S.; Tebyanian, H.; Ebrahimzadeh, M.A.; Goli, H. R. The effect of Citrullus colocynthis extracts on Streptococcus mutans, Candida albicans, normal gingival fibroblast and breast cancer cells. $J$ Biol Res 2019, 92, https://doi.org/10.4081/jbr.2019.8201.

27. Khojaste, M.; Yazdanian, M.; Tahmasebi, E.; Shokri, M.; Houshmand, B.; Shahbazi, R. Cell Toxicity and inhibitory effects of Cyperus rotundus extract on Streptococcus mutans, Aggregatibacter actinomycetemcomitans and Candida albicans. Eur J Transl Myol 2018, 28, https://doi.org/10.4081/ejtm.2018.7917.

28. Heidari, M.F.; Arab, S.S.; Noroozi-Aghideh, A.; Tebyanian, H.; Latifi, A.M. Evaluation of the substitutions in 212, 342 and 215 amino acid positions in binding site of organophosphorus acid anhydrolase using the molecular docking and laboratory analysis. Bratisl Lek Listy 2019, 120, 139-143, https://doi.org/10.4149/bll_2019_022.

29. Wu, C.; Qi, H.; Chen, W.; Huang, C.; Su, C.; Li, W.; Hou, S. Preparation and evaluation of a Carbopol/HPMC-based in situ gelling ophthalmic system for puerarin. Yakugaku Zasshi 2007, 127, 183-91, https://doi.org/10.1248/yakushi.127.183.

30. Khan, K.A.; Rhodes, C.T. Effect of compaction pressure on the dissolution efficiency of some direct compression systems. Pharm Acta Helv 1972, 47, 594-607. 
31. Shafiq, S.; Shakeel, F. Stability and self-nanoemulsification efficiency of ramipril nanoemulsion containing labrasol and plurol oleique. Clin. Res. Regul. Aff. 2010, 27, 7-12, https://doi.org/10.3109/10601330903571691.

32. Shafiq, S.; Shakeel, F.; Talegaonkar, S.; Ahmad, F.J.; Khar, R.K.; Ali, M. Development and bioavailability assessment of ramipril nanoemulsion formulation. Eur J Pharm Biopharm 2007, 66, 227-43, https://doi.org/10.1016/j.ejpb.2006.10.014.

33. Taherian, A.; Fazilati, M.; Moghadam, A.T.; Tebyanian, H. Optimization of purification procedure for horse F(ab')2 antivenom against Androctonus crassicauda (Scorpion) venom. Trop J Pharm Res 2018, 17, 409414, https://doi.org/10.4314/tjpr.v17i3.4.

34. Butani, D.; Yewale, C.; Misra, A. Amphotericin B topical microemulsion: formulation, characterization and evaluation. Colloids Surf B Biointerfaces 2014, 116, 351-8, https://doi.org/10.1016/j.colsurfb.2014.01.014.

35. Wang, Q.; Wong, C.H.; Chan, H.Y.E.; Lee, W.Y.; Zuo, Z. Statistical Design of Experiment (DoE) based development and optimization of DB213 in situ thermosensitive gel for intranasal delivery. Int. J. Pharm 2018, 539, 50-57, https://doi.org/10.1016/j.ijpharm.2018.01.032.

36. Raval, N.; Khunt, D.; Misra, M. Microemulsion-based delivery of triamcinolone acetonide to posterior segment of eye using chitosan and butter oil as permeation enhancer: an in vitro and in vivo investigation. $J$ Microencapsul 2018, 35, 62-77, https://doi.org/10.1080/02652048.2018.1425750.

37. Tenjarla, S. Microemulsions: an overview and pharmaceutical applications. Crit Rev Ther Drug Carrier Syst 1999, 16, 461-521.

38. Shah, J.; Nair, B.A.; Jacob, S.; Patel, K.R.; Shah, H.; Shehata, M.T.; Morsy, A.M. Nanoemulsion Based Vehicle for Effective Ocular Delivery of Moxifloxacin Using Experimental Design and Pharmacokinetic Study in Rabbits. Pharmaceutics 2019, 11, https://doi.org/10.3390/pharmaceutics11050230.

39. Fialho, S.L.; da Silva-Cunha, A. New vehicle based on a microemulsion for topical ocular administration of dexamethasone. Clin Exp Ophthalmol 2004, 32, 626-32, https://doi.org/10.1111/j.1442-9071.2004.00914.x.

40. Keipert, S.; Siebenbrodt, I.; Luders, F.; Bornschein, M. Microemulsions and their potential pharmaceutical application. Pharmazie 1989, 44, 433-44,

41. Mathis, G.A. Clinical ophthalmic pharmacology and therapeutics: ocular drug delivery. Vet. Ophthalmol 1999, 291-7.

42. Baranowski, P.; Karolewicz, B.; Gajda, M.; Pluta, J. Ophthalmic drug dosage forms: characterisation and research methods. ScientificWorldJournal 2014, 2014, 861904, https://doi.org/10.1155/2014/861904.

43. Kumar, R.; Sinha, V.R. Preparation and optimization of voriconazole microemulsion for ocular delivery. Colloids Surf B Biointerfaces 2014, 117, 82-8, https://doi.org/10.1016/j.colsurfb.2014.02.007.

44. Ammar, H.O.; Salama, H.A.; Ghorab, M.; Mahmoud, A.A. Development of dorzolamide hydrochloride in situ gel nanoemulsion for ocular delivery. Drug Dev Ind Pharm 2010, 36, 1330-9, https://doi.org/10.3109/03639041003801885.

45. Mahboobian, M.M.; Mohammadi, M.; Mansouri, Z. Development of thermosensitive in situ gel nanoemulsions for ocular delivery of acyclovir. $J$ Drug Del Sci Tech 2020, 55, https://doi.org/10.1016/j.jddst.2019.101400.

46. Morsi, N.M.; Mohamed, M.I.; Refai, H.; El Sorogy, H.M. Nanoemulsion as a novel ophthalmic delivery system for acetazolamide. Int J Pharm Pharm Sci 2014, 6, 227-36.

47. Idrees, M.; Rahman, N.; Ahmad, S.; Ali, M.; Ahmad, I. Enhance transdermal delivery of flurbiprofen via microemulsions: Effects of different types of surfactants and cosurfactants. Daru 2011, 19, 433-9.

48. Tayel, S.A.; El-Nabarawi, M.A.; Tadros, M.I.; Abd-Elsalam, W.H. Promising ion-sensitive in situ ocular nanoemulsion gels of terbinafine hydrochloride: design, in vitro characterization and in vivo estimation of the ocular irritation and drug pharmacokinetics in the aqueous humor of rabbits. Int J Pharm 2013, 443, 293305, https://doi.org/10.1016/j.ijpharm.2012.12.049.

49. Lawrence, M.J.; Rees, G.D. Microemulsion-based media as novel drug delivery systems. Adv Drug Deliv Rev 2000, 45, 89-121, https://doi.org/10.1016/s0169-409x(00)00103-4.

50. Calvo, P.; Vila-Jato, J.L.; Alonso, M.J. Comparative in vitro evaluation of several colloidal systems, nanoparticles, nanocapsules, and nanoemulsions, as ocular drug carriers. J Pharm Sci 1996, 85, 530-536, https://doi.org/10.1021/js950474+. 